daß der Zwang zur Bekanntmachung eines Bekenntnisses lediglich auf höchste Entscheidungsträger beschränkt bleiben sollte. Auch der bedauernswerte Volksschulrektor, der nunmehr nach dem Willen des bayerischen Gesetzgebers im Einzelfall zu befinden hat, ob das Kreuz im Klassenzimmer bleibt oder nicht, oder der Steuerbeamte, der mit dem Steuerpflichtigen über die Höhe der Kirchensteuer hadert, oder die vielen anderen Staatsdiener, die von Amts wegen mit dem religiös-weltanschaulichen Bekenntnis in Kontakt kommen können, beim Kirchenbau, in Kindergartenangelegenheiten, im Friedhofswesen und wo immer, würden vermutlich wohl glaubenstreuer und erst recht rechtstreuer entscheiden, wenn ihre Bekenntnishaltung dem verehrlichen Publikum amtswegig zugänglich wird.

Andererseits: Das staatliche Recht kennt vielleicht aus guten Gründen keine katholischen oder protestantischen, keine christ- oder sozialdemokratischen Staatsdiener, sondern einfach nur Bundes- und Landesbeamte und -richter. Es ist offenbar (noch) von der Vorstellung beseelt, daß jeder im öffentlichen Dienst Beschäftigte ohne Rücksicht auf seine persönlichen Überzeugungen und Einstellungen seine Pflicht erfüllt, wie er es, meist unter Beanspruchung der religiösen Eidesformel, geschworen hat. Daß sich freilich das hohe Ideal trotz der Anrufung Gottes in den Niederungen der Alltagspraxis nicht immer und unbedingt wiederfindet, ist ein Gemeinplatz, der nicht sogleich zur Anpassung des Rechts an die Wirklichkeit nötigt. Wer würde schon allein wegen der Differenz zwischen Soll und Ist die Abtreibung straflos stellen und den Steuerbetrug legalisieren? Zu glauben aber, daß die Mitteilung der persönlichen Einstellung in Bekenntnisfragen - und wer weiß mit welchen notwendigen Präzisierungen (vielleicht: "protestantisch, jedoch nicht sehr", oder: "katholisch, aber Lefèbre«) - die verfassungsgerichtliche oder welch andere Rechtsfindung auch immer fördern könnte, ist mitsamt der implizierten unglaublichen Unterstellung, die Bundesverfassungsrichter hätten bei Kundgabe ihrer religiösen Einstellung in irgendeinem Sinne anders entschieden, von beeindruckender Absurdität.

Ansonsten muß man schon aus Bayern kommen, um die Konfessionalisierung des öffentlichen Dienstes wieder diskussionsfähig zu machen und zu bekräftigen, daß es, wenigstens im Lande populistischer Bewegungen für Biergärten und Schulkreuze, genügt, wenn sich der Fortschritt auf die technisch-industrielle Seite der Gesellschaft beschränkt. Gleichwohl: Die persönliche Gläubigkeit ist aktiv und passiv von den Dienstgeschäften zu separieren. Sie ist nun wirklich Privatsache. Niemanden dürfte deshalb letztendlich interessieren, wie sich Herr Dr. Eber] persönlich bekennt. Es genügt im übrigen bereits seinem Drang nach schonungsloser Selbstdarstellung zu lesen, was er schreibt.

\title{
Betrifft: Kritische Justiz
}

"... Am Abend nach Barbaras Geburtstag rief Uschkurat an, der Richter ohne Furcht und Tadel, und fing nicht, wie es der Beamte Fink erwartete, sofort vom Fall an, sondern von den Asylverfahren, mit denen er täglich beschäftigt war. Täglich hatte er die Anträge kurdischer Asylsuchender zu bearbeiten, zu entscheiden. Noch am späten Abend loderte er vor Zorn, wenn er die Ignoranz der Politiker beschrieb, die sich über die Lage dieser Asylbewerber hinweglogen. Der Beamte Fink wartete ruhig und konzentriert nur auf eine Uschkuratsche Atempause, in die er hineinfragen konnte, ob der Richter Uschkurat etwas von dem Kollegen gehört habe, der 
Beziehungen hätte zur Zeitschrift Betrifft Justiz, ob er den habe bitten können, noch einmal nachzuhaken bei dem Stuttgarter Verlag. Der Richter hat gehört, die in Stuttgart hätten sich noch nicht einigen können über diesen Artikel, er werde aber gern morgen seinen Stuttgarter Bekannten noch einmal anrufen und dem noch einmal klarmachen, wie wichtig es wäre, daß dieser Aufsatz in Betrifft Justiz erschiene. Der Beamte Fink bedankte sich und notierte, daß er seinem Anwalt morgen mitzuteilen habe, der unter des Anwalts Namen dort eingereichte Artikel werde in Stuttgart lebhaft diskutiert, die Aussichten seien nicht schlecht. Richter Uschkurat werde dafür sorgen, daß sie noch besser würden. Da der Artikel schon von der Redaktion Kritische Justiz abgelehnt und dem Anwalt mit Floskeln zurückgeschickt worden war, hatte der Beamte Fink Angst, der Anwalt könne durch solche Mißerfolgserlebnisse die Lust verlieren. Er mußte seinen Anwalt Erfolg erleben lassen, also einen Artikel, den er mit dem Anwalt entwickelt hatte, in einer angesehenen Zeitschrift unterbringen. Er mußte für Vorgänge sorgen, für Bewegung, daß der Anwalt erlebte: Es tut sich etwas, der Fall lebt. Zum Glück konnte er seinem Anwalt einen Tag später melden, was Georg Gelter, der Kämpferische, gemeldet hatte: Imprimatur bringt's. Und Imprimatur brachte es. Fink holte das Paket mit zwanzig Exemplaren am Hauptbahnhof ab. Die Winteroffensive lief an. Gierig graste er den Text ab. Gelter hatte doch noch geändert. Leibniz hatte dringend geraten, in dem Text das Wort Opfer durch der Geschädigte zu ersetzen. Gelter hat Opfer vorgezogen. Franz Karl Moors Kommentar: In der FAZ wär' der Artikel Gold, aber in Imprimatur ... Und blies ein unsichtbares Stäubchen von seiner Handfläche...«

Aus: Martin Walser, Finks Krieg, Roman, Suhrkamp Verlag 1996, S. 95 f.

\section{Monika Frommel \\ Das Kreuz mit der Trennung von Staat und Kirche}

Im Kirchlichen Amtsblatt für die Diözese Mainz wurden im Dezember r 995, kurz vor Weihnachten, die vorläufigen Bischöflichen Richtlinien für katholische Schwangerschaftskonfliktberatungsstellen abgedruckt. Sie enthalten in $\$ 6$ den interessanten Hinweis, daß es wweder mit dem Selbstverständnis katholischer Beratungsarbeit noch mit dem Schutzkonzept der Beratungsregelung vereinbar « sei, „Ratsuchende auf Ärzte, Krankenhäuser oder Einrichtungen hinzuweisen, die Schwangerschaftsabbrüche vornehmen«.

Nun hätte niemand erwartet, daß ausgerechnet katholische Einrichtungen solche Dienstleistungen erbringen, wohl aber, daß sie sich an das reformierte Gesetz halten. Aber auch dies scheint in Zeiten zaghafter Liberalisierungen nicht mehr gewünscht zu sein. Ratsuchende werden zielorientiert beraten. Wenn sie von ihrem Recht auf Ergebnisoffenheit Gebrauch machen, werden katholische Beraterinnen angewiesen, ihr Mißfallen indirekt zum Ausdruck zu bringen. Sie verweigern dann jede Unterstützung beim Ausfüllen der komplizierten Formblätter (Finanzierung des Abbruchs durch die Länder über die Krankenkassen). In der Richtlinie klingt dies so: Mit dem Selbstverständnis der Beratungsarbeit sei es nicht vereinbar, "Anträge zur Finanzierung von Schwangerschaftsabbrüchen auszulegen, auszufüllen oder dabei unterstützend mitzuwirken«. $\$ 4$ geht noch weiter: »Katholische Beratungsstellen lehnen eine Beratung dann ab, wenn für die beratende Person offensichtlich ist, daß 